Veen, E.D. van, Jacobs, J.B., Bensing, J.M. Assessment of distress associated with tinnitus. Journal of Laryngology and Otology: 1998, 112(3), p. 258-263

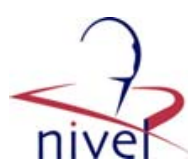

\begin{tabular}{|l|l|}
\hline $\begin{array}{l}\text { Postprint } \\
\text { Version } \\
\text { Journal website }\end{array}$ & 1.0 \\
\hline Pubmed link & $\underline{\text { http://journals.cambridge.org//action/displayAbstract?fromPage=online\&aid=10 }}$ \\
\hline DOI & $\underline{\text { http://www.ncbi.nlm.nih.gov/pubmed/9624375 }}$ \\
\hline
\end{tabular}

This is a NIVEL certified Post Print, more info at http://www.nivel.eu

\title{
Assessment of distress associated with tinnitus
}

\section{E. D. VAN VEEN*, J. B. JACOBS†, J. M. BENSING*}

From the Department of Clinical Psychology and Health Psychology*, University of Utrecht, and the Department of Otolaryngology $\dagger$, University Hospital Rotterdam, The Netherlands.

\begin{abstract}
This paper focuses upon the quality of the Dutch translation of the STSS (Subjective Tinnitus Severity Scale), a scale which assesses the severity of tinnitus and the related distress. Research has been done on the psychometric qualities of this scale, its relationship with loudness-matching procedures and several psychological variables. Data presented on 104 tinnitus patients demonstrated the reliability of the STSS with a coefficient alpha of 0.71. Factor analysis revealed four factors: emotional distress, intrusiveness, annoyance and cognitive distress. With regard to the validity, significant correlations of a moderate degree were found with several unitary subjective scales measuring the same construct $\left(\mathrm{r}_{\mathrm{s}}=0.50\right.$, $/ ?<0.001$ and $\left.\mathrm{r}_{\mathrm{s}}=0.43, / ?<0.01\right)$. Correlational research demonstrated that the STSS is independent of the loudness of tinnitus as measured by matching procedures $\left(\mathrm{r}_{\mathrm{s}}=0.00\right)$.

In contrast, significant correlations of a moderate magnitude were found with anxiety $\left(\mathrm{r}_{\mathrm{s}}=\right.$ $0.33, / ?<0.001)$ and depression $\left(\mathrm{r}_{\mathrm{s}}=0.31, \mathrm{p}<0.01\right.$ and $\left.\mathrm{r}_{\mathrm{s}}=0.35, / ?<0.001\right)$.
\end{abstract}

\section{INTRODUCTION}

Tinnitus is the experience of hearing a sound from one or both ears, or in the head, occurring in the absence of any relevant external stimuli. Other auditory difficulties often accompany tinnitus. Epidemiological studies have made it plausible that in Western industrialized countries 32 per cent of the adult population reports tinnitus (National Centre for Health Statistics, 1980). In up to one-third of these cases, tinnitus is of a severe degree and the quality of life is seriously disturbed (Coles, 1984; Axelsson and Ringdahl, 1989). Tinnitus can be viewed as a multifaceted phenomenon which results in a broad range of complaints, such as irritability, depression, inability to relax, sleep- and concentration problems (Tyler and Baker, 1983).

The objective assessment of the severity of a subjective state like tinnitus is problematic, since sound-intensity matching may not correspond to subjective complaints (Meikle and Taylor-Walsh, 1984). That is why subjective questionnaires are necessary for a full understanding of the patients problems and the severity of tinnitus complaints. Therefore, in recent years several questionnaires have been developed to measure tinnitus complaints regarding its assumed multidimensionality (Erlandsson, 1992).

A few shorter questionnaires focus on a more global one-dimensional assessment of tinnitus severity (Hiller et al., 1994), one of which is the Subjective Tinnitus Severity Scale 
Veen, E.D. van, Jacobs, J.B., Bensing, J.M. Assessment of distress associated with tinnitus. Journal of Laryngology and Otology: 1998, 112(3), p. 258-263

(STSS) developed by Halford and Anderson (1991a) (see appendix for STSS items). This questionnaire was developed to test whether it was justified to measure tinnitus severity as a unitary concept. This scale measures tinnitus severity according to the degree to which tinnitus is intrusive, prominent and distressing (Halford and Anderson, 1991a). Halford and Anderson (1991a) have carried out research into the psychometric qualities of the STSS, such as reliability, validity and its relationships with questionnaires measuring anxiety and depression.

With relation to reliability, the coefficient alpha turned out to be 0.84 . This measurement of internal consistency reflects the extent to which the different properties of a scale all relate to the same underlying dimension. Guttman's split-half, the correlation between the eight odd items and the eight even items in the survey sample $(n=112)$, produced a value of $\mathrm{r}_{2}=0.72$ $(p<0.001)$. In the clinical sample $(n=30)$ these indicators of internal consistency turned out to be 0.90 respectively $\mathrm{r}_{2}=0.75(\mathrm{p}<0.001)$.

In a factor analytical study of the STSS, five clearly dissassociated factors, explaining 61.6 per cent of the variance, were obtained. Only the primary factor, accounting for 30.9 per cent, was labelled; this 'distress intrusion factor' appeared to be a composite of the sensory intrusiveness of tinnitus and affective maladaption.

The validity was established in the clinical sample, where STSS scores were found to correlate signifi- cantly with two independent clinical ratings of severity $\left(\mathrm{r}_{2}=0.76, \mathrm{p}<0.001\right.$ and $\left.\mathrm{r}_{2}=0.73, \mathrm{p}<0.001\right)$.

Examining the relationship between the STSS scores and audiometric loudness-matching techniques revealed at $1 \mathrm{kHz}$ a significant correlation of the scale with the tinnitus loudness match $\left(\mathrm{r}_{2}=0.48, \mathrm{p}<0.01\right)$ and with the tinnitus sensation level $\left(\mathrm{r}_{2}=0.36, \mathrm{p}<0.05\right)$, but not with the threshold value. On the other hand, at the tinnitus frequency it was the threshold and loudness match that correlated with the STSS $\left(\mathrm{r}_{2}=0.39, \mathrm{p}<0.05\right.$ respectively $\mathrm{r}_{2}=0.41$, $\mathrm{p}<0.05$ ), while the tinnitus sensation level did not (Halford and Anderson, 1991a). In line with prior studies (Reich and Johnson, 1984; Stephens and Hallam, 1985) they found that tinnitus patients showed increased psychopathology. Elevated tinnitus severity was significantly associated with both higher mean anxiety, as measured by the trait component at Spielberger's State- Trait Anxiety Inventory, form Y, and depressive tendency, using the Depressive Tendency Questionnaire. The degree of direct association between either psychological variable and the STSS was, while significant, of a low magnitude $\left(\mathrm{r}_{2}=0.28\right.$, one-tailed $\mathrm{p}<0.01$ respectively $\mathrm{r}_{2}=0.32$, one-tailed $\mathrm{p}<0.001$ ) (Halford and Anderson, 1991b). The authors argued that the STSS proved its usefulness as a simple, reliable and valid method. Since the clinical sample was small $(n=30)$, extensive clinical data on different populations were recommended by the authors.

The main purpose of the present study was to investigate the usefulness of the STSS for our Dutch clinical population. We therefore studied the following:

(1) Is the internal consistency of the STSS high enough to regard the STSS as a reliable instrument? Are the items measuring the same underlying construct, or do the low intercorrelations argue for the existence of several factors? Furthermore, we want to give an estimation of the validity to see if it is legitimate to consider the STSS as a measure of subjective tinnitus severity.

(2) The relationship of subjective severity of tinnitus with loudness as measured by matching procedures. Several studies have found only poor associations between selfreported severity and audiologically measured loudness of tinnitus (Jakes et ai, 1986).

(3) The relationship between severity of complaint and psychological variables, such as depression, anxiety and locus of control. Often correlations of the severity of tinnitus with scores on depression and anxiety scales are reported (Halford and Anderson, 1991b; Hiller and Goebel, 1992). Research on the predictors of several aspects of tinnitus resulted in the finding that perceived control over tinnitus seems to facilitate adaption and implies a decrease in discomfort (Scott et al., 1989). According to this, we could expect that the STSS correlates negatively with an internal locus of control. 


\section{METHOD}

\section{Subjects}

The random sample consists of 104 tinnitus patients, 54 males and 50 females, who were consecutive patients - in a period of two years referred for tinnitus from primary and secondary medical care - in the Audiological Centre of the ENT Department of the University Hospital in Rotterdam. For all subjects, tinnitus was their primary complaint and a hearing aid did not mask the tinnitus. Tinnitus did not appear to be the only audiological problem at the moment of reference to the audiological centre (Table I). The mean age was 50.67 years $(\mathrm{SD}=11.27)$. The mean duration of the tinnitus was 4.26 years $(\mathrm{SD}=3.93)$.

\section{[TABLE 1]}

\section{Measures and procedures}

When the patients are referred, a multidisciplinary screening takes place, which consists of ENT medical examination, an audiological intake, audiometric examination and a psychological examination. The data collection includes:

(a) Subjective Tinnitus Severity scale. Severity was measured by a sixteen item binary response scale (Yes/no), the total score range being 0-16. With permission from the authors, two independent translators, one of them bilingual, have translated the STSS into Dutch and back into English.

(b) Visual analogue scales, aiming to assess several complaint dimensions, in which the patient represents his opinion about the given statement by placing marks on a horizontal line of 100 millimetres, which is anchored by two extremes. The information was then transformed to a 100 point scale, in which a value of 0 indicates minimal agreement with the thesis, and a value of 100 represents maximal agreement.

The statements are:

1. 'How much annoyance do you experience from your tinnitus'.

2. 'The degree to which I have a hold on my own life, I find ... '.

3. 'The degree to which I expect to master my tinnitus, is ... '.'

(c) Impact of tinnitus on daily life was measured by a semi-structured interview held by the centre's audiologist. On the question 'How do you assess your tinnitus?', the seven point scale contains the following answering possibilities:

1. absent.

2. hardly audible.

3. audible, but does not cause nuisance.

4. irritating, but does not influence work or social activities.

5. irritating to a degree that is difficult to perform some duties or activities.

6. irritating and distracting; concentration problems; only simple work can be performed.

7. exhausting tinnitus; work practically impossible.

(d) Sensory aspects of tinnitus measured by loudness- matching. In this method tinnitus is matched to a sound delivered to the contralateral ear.

(e) Utrechtse Coping Lijst (UCL) (Schreurs et al., 1993). This questionnaire is a valid and reliable method to measure general coping behaviour in problem situations. Only the 'depression reaction pattern' scale of this questionnaire was used.

(f) A Dutch adaptation of the Symptom Checklist- 90 (SCL) (Arrindell and Ettema, 1986) which contains 90 self-rated psychopathological signs and symptoms. From the nine scales representing clinical syndromes, the 'depression' and the 'anxiety' scales were used. 
(g) Pijn Cognitie Lijst (PCL) (Vlaeyen etal, 1990), which assesses specific cognitive strategies for coping with pain. The PCL is adapted for tinnitus with permission from the author. Two scales are useful in representing the construct of locus of control:

1. positive expectation. Persons with high scores on this scale appear to have at one's disposal successful coping skills and can be characterized by an internal locus of control.

2. reliance on health care. Patients with high scores expect that others will find remedies to relieve their pain and their cognitions are marked by an external locus of control (Vlaeyen et al., 1990).

\section{Statistical analysis}

We employed Conbrach's coefficient $\alpha$ and the Guttman-split-half coefficient to investigate the reliability of the STSS. To trace if the scale measures an unitary construct, the intercorrelations of the separate items were studied; if these turned out to be low, factor analysis were applied. If the validity of the STSS was considered as acceptable, the correlations of the STSS with other subjective scales, measuring the same construct, were high; also, the correlations of the scale with loudness matching procedures were calculated. The sensitivity of the STSS to age and duration of the tinnitus complaints was examined by the correlations between these variables. The correlations of the STSS with scales from the SCL-90 and UCL, were calculated to investigate the relationship with psychological disturbances. With respect to the relationship with locus of control, correlations with the adapted PCL and two visual analogue scales were computed. Since the STSS does not meet the requirements of the normality assumption, all correlations were calculated by Spearman's Rank correlation. This correlation coefficient $\left(\mathrm{r}_{\mathrm{s}}\right)$ has been calculated in the same way as Person product moment efficient, except it is based on rank orders.

\section{RESULTS}

\section{Reliability}

In our research sample, the internal consistency of the STSS, as expressed by Conbrach's coefficient $\alpha$, turned out to be 0.71 , just above the 0.70 , which is considered the minimum value for regarding a scale as reliable.

The Guttman- split- half coefficient, also an indicator of reliability, comes to 0.73 .

\section{Item analysis}

With the exception of the item 'Do you often have a day or more completely free from tinnitus', all of the individual items correlate significantly $(\mathrm{p}<0.01)$ with the total STSS score (Table II). This is indicative of both the internal consistency and the utility of the individual items.

It is striking that two questions ('Would you say that, you would have a much more enjoyable life, if you did not have tinnitus' and 'Is your tinnitus present for at least part of every day') have nearly always been answered affirmatively (99 and 97 per cent respectively). These two items do not appear to differentiate between the high and low scores of the STSS, at least not in our sample. The intercorrelation of the items is weak, although the amount of negative correlations is restricted (Table III). The low correlations could be caused by the multidimensionality of the questionnaire. To test this hypothesis, we applied factor analysis which provided six factors with an eigenvalue greater than 1.00, explaining 62.7 per cent of the total variance. The six-factor model, however, is not useful, since a lot of items have loadings on more than one factor. Because the sixth factor consists of only one item, and consequently does not contribute anything to the explanation, we decided to reject this model. One way to supersede the real number of factors is to use Cattel's method, which 
includes drawing up a scree plot. The scree indicates that the number of factors should be three or four. The four-factor model, which explains 49.6 per cent of the total variance, is preferable to the three-factor model, since the first contains less double loadings of the items, and also has higher loadings of the items on the factors. The four-factor model also offers better opportunities for interpretation of the factors. The factors are:

Factor one: explains 21 per cent of the variance; 'Emotional distress'.

- Does your tinnitus often interfere with your ability to relax? $(0.80)$

- Does your tinnitus cause you problems in getting off to sleep? $(0.70)$

- Would you say, that although the tinnitus can be irritating, it does not get you down?

$(0.64)$

- Does your tinnitus sometimes make it difficult for you to concentrate? (0.49)

- Does your tinnitus frequently upset you? (0.47)

- Do you find your tinnitus bothers you, when you are doing something physical, like dressing or gardening? (0.40) Is your tinnitus very noisy? $(0.35)^{1}$

Factor two: explains 11.7 of the variance: 'Intrusiveness'.

- Is your tinnitus present for at least part of every day? (0.77)

- Would you say, you would have a much more enjoyable life, if you did not have tinnitus? $(0.76)$

- Do you often have a day or more completely free from tinnitus? (0.62)

- Is your tinnitus very noisy? $(0.53)$

Factor three: explains 8.9 per cent of the variance: 'Annoyance'.

- Do you sometimes go for hours without noticing your tinnitus? (0.77)

- When you are busy, do you quite often forget about your tinnitus? (0.74)

- Would you say that generally the tinnitus does not bother you? (0.44)

- Is it unusual for your tinnitus to annoy you when you are trying to read or watch television? (0.36)

- Do you find your tinnitus bothers you, when you are doing something physical, such as dressing or gardening? $(0.36)^{1}$

Factor four: explains 7.8 per cent of the variance: 'Cognitive distress'.

- Are you almost always aware of your tinnitus? (-0.60)

- Do you often talk about the problems your tinnitus causes to others? (0.58)

- Does your tinnitus frequently upset you? (0.45)*

The first factor measures the affective component of tinnitus as confirmed by its significant correlations with each of the three scale measuring the psychological disturbances (Table IV). The 'intrusiveness' factor, in comparison with the three other factors, has the highest correlation with the audiological matched loudness of tinnitus. The third factor 'annoyance' has a significant correlation with the visual analogue scale 'How much annoyance do you experience from your tinnitus'.

[TABLE 2]

\footnotetext{
${ }^{1}$ Variables having a higher loading on another factor. Between brackets, the loading on the factors are mentioned.
} 
[TABLE 3]

\section{[TABLE 4]}

\section{Validity}

To estimate the validity, the above mentioned visual analogue scale had a mean of 73.56 $(\mathrm{SD}=19.52)$ and showed a significant correlation $\left(\mathrm{r}_{\mathrm{s}}=0.50\right)$ with the STSS $(\mathrm{p}<0.001$, onetailed probability). The seven point scale, from the semi-structured interview with the audiologist, 'How do you assess your tinnitus', with a mean score of 3.95 (SD =1.07), also had a significant moderate correlation ( $\mathrm{r}_{\mathrm{s}}-0.43, \mathrm{p}<0.01$, one-tailed probability). The STSS appears to be independent of the audiological assessed loudness of tinnitus considering the correlation between them $\left(r_{s}=0.00\right)$. The total score of the STSS turned out to be unrelated to the duration of the tinnitus complaints and the age of our respondents (for both: $r_{s}=0.06$, two-tailed probability).

\section{Relationship with depression and anxiety}

For our study to the existence of psychological disturbances accompanying tinnitus, in total 99 subjects have filled in the SCL-90 and the UCL. The 'depression reaction pattern' of the latter showed a mean of 19.06 ( $\mathrm{SD}=7.01)$ which is quantified by the test as a high score. The mean of the 'depression' scale from the SCL-90 was 31.28 ( $\mathrm{SD}=12.20)$ which also fell into the category 'high score'. The correlation data demonstrated that the degree of direct association between depression and tinnitus, while significant, was of low magnitude (STSS/UCL $r_{s}=0.31$, one-tailed $p<0.01 ;$ STSS/SCL- $90 r_{s}=0.35$, one-tailed $p<0.001$ ). The mean of the anxiety scale of the SCL-90 was 19.06 which also is regarded as a high score. Tinnitus severity was also significant associated with higher anxiety as is shown by the moderate correlation $\left(\mathrm{r}_{\mathrm{s}}=0.33\right.$, one-tailed $\left.\mathrm{p}<0.001\right)$. For all mentioned psychological scales, the T-test showed higher scores in women than in men, but this distinction between the sexes is not significant.

\section{Relationship with locus of control}

The two scales of the adapted PCL, 'positive expectation' and 'trust in health care' $(n=67)$ appeared to be independent of the scores of the STSS. For further examination of a possible connection of the locus of control with the subjective experience of tinnitus, we used two visual analogue scales. The mean of the scale 'the degree to which I have a hold on my own life' was $39.38(\mathrm{SD}=27.07)$, and 'the degree in which I expect to master my tinnitus' had a mean of $51.50(\mathrm{SD}=27.48)$. The significant correlations with the total score on the STSS turned out to be negative $\left(r_{s}=-0.27\right.$, one-tailed $p<0.01$ respectively $r_{s}=-0.24$, one-tailed $\mathrm{p}<0.01)$. These two visual analogue scales were relatively independent on each other $(\mathrm{r}=$ 0.11 ); the degree to which one has a hold on one's own life does not consequently have any influence on the degree with which one expects to master one's tinnitus.

\section{DISCUSSION}

Our first question, concerning the reliability, produced a Cobrach's « of 0.71 , which is slightly above the minimum acceptable value of 0.70 and below the reasonable reliability coefficient of the original STSS. The only item which did not correlate significantly with the STSS also had very low correlation in Halford's research. 
The usefulness of two other items turned out to be doubtful, considering their insensitivity in discriminating between high and low scores of the STSS. The moderate reliability together with the weak intercorrelations of the items seemed to reject the supposed unidimensional structure of the scale. This is confirmed by the application of factor analysis which resulted in denomination of four factors: emotional distress, intrusiveness, annoyance and cognitive distress. The first two factors are probably a split-up of Halford's distressintrusion factor. Three of our factors are analogous to the factor analytical findings of Hiller and Goebel (1992); the annoyance factor corresponds with the disability/ handicap factor of the Tinnitus Handicap/Support Scale (Erlandsson et al., 1992). In contrast to the majority of tinnitus questionnaires, we did not find factors which are only related to somatic aspects.

This could be explained by the absence of physiological items compared to other tinnitus questionnaires, all items containing audiological aspects loaded on the intrusiveness factor. Neither this factor, nor the total STSS score, correlated with the loudness of tinnitus as measured by matching procedures.

With regard to the validity, the STSS had significant correlations of a moderate degree with several unitary subjective scales, which also measured the subjective experience of tinnitus and appeared to be independent of age and of the duration of the tinnitus complaints. In agreement with Halford, moderate but significant correlations with the anxiety and depression scales were found. The mean scores of this study population on these scales, compared with the norm groups, could be regarded as high, thus it may be concluded that severe tinnitus is often accompanied by psychological disturbances. We also found support for our hypothesis that perceived control (locus of control), both in terms of general life events and more specifically of the emotional distress of tinnitus, is related to the severity of tinnitus. However, the correlations were weak.

Our study considered of clinical patients with tinnitus as a main complaint. As expected the mean STSS total score exceeded those of Halford's selfhelp group, which amounts to 8.1. The degree of severity of tinnitus in our population is also reflected by the absence of the low total scores; the values $0,2,3$ and 4 did not even exist. Taking into account the relatively small size of the sample, it is not possible to translate specific STSS scores values into precise severity classifications. More heterogeneous normative data are needed before using the total scores to classify a patient's tinnitus complaints.

On the basis of our research we may conclude that for clinical purposes, the STSS does not add useful information for matching patients to treatment. Furthermore, the STSS turned out to be not sensitive enough to monitor and evaluate a patient's progress during our treatment program (internal publication).

A scale explicitly bringing out the multidimensionality of tinnitus, bears a better clinical application. One of them is the Tinnitus Questionnaire (TQ) produced by Hallam et al. (1988), which contains a broader spectrum on tinnitus related complaints. This scale contains six factors, reflecting the multifaceted nature of chronic tinnitus, derived from both factor analysis and clinical evidence (Hiller and Goebel, 1992; Hiller et al., 1994). Currently, research on the validity of the Tinnitus Questionnaire is executed in our Dutch tinnitus clinics. Collaborating this way will lead to a better understanding of the complex nature of tinnitus complaints and a further enhancing of the comparability of studies on prediction and outcome of treatment.

\section{REFERENCES}

Arrindell, W. A., Ettema, J. H. M. (1986) SCL-90. Symptom Checklist. Handleiding bij multidimensionale psychopathologie- indicator. Swets and Zeitlinger, Lisse.

Axelsson, A., Ringdahl, A. (1989) Tinnitus- a study of its prevalence and characteristics. British Journal of Audiology 23: 53-62. 
Veen, E.D. van, Jacobs, J.B., Bensing, J.M. Assessment of distress associated with tinnitus.

Journal of Laryngology and Otology: 1998, 112(3), p. 258-263

Coles, R. R. A. (1984) Epidemiology of tinnitus: (1) Prevalence. Journal of Laryngology and Otology (Suppl 9): 7-15.

Erlandsson, S. I. (1992) Assessments of tinnitus: a review. Proceedings of the IV International Tinnitus Seminar, Bordeaux, France, August 27-30, 1991 (Aran, J. M., Dauman, R., eds). Tinnitus 91: 547-549.

Erlandsson, S. I., Hallberg, L R. M, Axelsson, A. (1992) Psychological and audiological correlates of perceived tinnitus severity. Audiology 31: 168-79.

Halford, J. B. S., Anderson, S. D. (1991a) Tinnitus severity measured by a subjective scale, audiometry and clinical judgment. Journal of Laryngology and Otology 105: 89-93.

Halford, J. B. S., Anderson, S. D. (1991b) Anxiety and depression in tinnitus sufferers. Journal of Psychosomatic Research 35: 383-390.

Hallam, R. S., Jakes, S. C, Hinchcliffe, R. (1988) Cognitive variables in tinnitus annoyance. British Journal of Clinical Psychology 27: 213-222.

Hiller, W., Goebel, G. (1992) A psychometric study of complaints in chronic tinnitus. Journal of Psychosomatic Research 36: 337-348.

Hiller, W., Goebel, G., Rief, W. (1994) Reliability of self-rated tinnitus distress and association with psychological symptom patterns. British Journal of Clinical Psychology 33: 231-239.

Jakes, S. C, Hallam, R. S., Chambers, C. C, Hinchcliffe, R. (1986) Matched and selfreported loudness of tinnitus: methods and sources of errors. Audiology 25: 92-100. Meikle, M., Taylor-Walsh, E. (1984) Characteristics of tinnitus and related observations in over 1800 tinnitus clinic patients. In: Proceedings of the Second International Tinnitus Seminar. (Schulman, A., ed.). Journal of Laryngology and Otology (Suppl 9): 17-21. National Center for Health Statistics (1980) Basic data on hearing levels of adults 25-74 years, United States 1971- 1975. Vital and Health Statistics Publication Series (Series 11, no. 215). Hyattsville, MD: US Department of Health Education and Welfare.

Reich, G. E., Johnson, R. M. (1984) Personality characteristics of tinnitus patients. In: Proceedings of the Second International Tinnitus Seminar. (Schulman, A., ed.). Journal of Laryngology and Otology (Suppl 9): 228-232.

Schreurs, P. J. G., Willige, G. van de, Bronschot, J. F., Tellegen, B., Graus, G. M. H. (1993) De Utrechtse Coping lijst: Omgaan met problemen en gebeurtenissen. Swets and Zeitlinger, Lisse.

Scott, B., Lindberg, P., Melin, L., Lyttkens, L. (1989) Predictors of tinnitus discomfort, adaption and subjective loudness. British Journal of Audiology 24: 51-62.

Stephens, R. D. G., Hallam, R. S. (1985) The Crown-Crisp experiential index in patients complaining of tinnitus. British Journal of Audiology 19: 151-158.

Tyler, R. S., Baker, L. J. (1983) Diffculties experienced by tinnitus sufferers. Journal of Speech and Hearing Disorders 48: 150-154.

Vlaeyen, J. W. S., Geurts, S. M, Eak, H. van, Snijders, A. M.

J., Schuerman, J. A., Groenman, N. H. (1990) Pijn Cognitie Lijst-experimentele versie. Swets and Zeitlinger, Lisse.

Address for correspondence: Mrs J. B. Jacobs, ENT Department, Dr Molewaterplein 40, 3015 GD Rotterdam, University Hospital Rotterdam, The Netherlands. 
Veen, E.D. van, Jacobs, J.B., Bensing, J.M. Assessment of distress associated with tinnitus.

Journal of Laryngology and Otology: 1998, 112(3), p. 258-263

TABLES

TABLE I

OTOLOGICAL DIAGNOSES $(\mathrm{N}=104)$

\begin{tabular}{lc} 
Cochlear tinnitus of unknown origin & 50 \\
Idiopathic tinnitus & 16 \\
Noise damage & 7 \\
Otosclerosis & 6 \\
Radical mastoidectomy & 4 \\
Ménière's disease & 3 \\
Eustachian tube disease & 3 \\
Presbyacusis & 2 \\
Myoclonus & 2 \\
Sudden deafness & 2 \\
Otitis externa & 2 \\
Otitis media & 2 \\
Retrocochlear pathology & 2 \\
Temporomandibular joint syndrome & 1 \\
Tympanic membrane perforation & 1 \\
Labyrinthectomy & 1 \\
\hline
\end{tabular}

TABLE II

CORRELATION COEFFICIENTS BETWEEN EACH ITEM AND THE TOTAL SCORE OF THE STSS

\begin{tabular}{rccc}
\hline Item & $\mathrm{r}_{\mathrm{s}}$ & $p$ & $\%$ \\
\hline 1 & $.53(.47)$ & $p=.000$ & $86 \%(67)$ \\
2 & $.37(.46)$ & $p=.000$ & $89 \%(73)$ \\
3 & $.46(.49)$ & $p=.000$ & $24 \%(31)$ \\
4 & $.42(.47)$ & $p=.000$ & $66 \%(52)$ \\
5 & $.37(.63)$ & $p=.000$ & $70 \%(61)$ \\
6 & $.52(.52)$ & $p=.000$ & $67 \%(35)$ \\
7 & $.47(.65)$ & $p=.000$ & $89 \%(68)$ \\
8 & $.57(.66)$ & $p=.000$ & $35 \%(53)$ \\
9 & $.15(.22)$ & $p=.064$ & $89 \%(88)$ \\
10 & $.47(.36)$ & $p=.000$ & $41 \%(20)$ \\
11 & $.31(.25)$ & $p=.001$ & $97 \%(97)$ \\
12 & $.66(.50)$ & $p=.000$ & $68 \%(72)$ \\
13 & $.53(.48)$ & $p=.000$ & $63 \%(45)$ \\
14 & $.35(.29)$ & $p=.000$ & $35 \%(43)$ \\
15 & $.45(.20)$ & $p=.000$ & $67 \%(46)$ \\
16 & $.34(.48)$ & $p=.000$ & $99 \%(80)$ \\
\hline
\end{tabular}

Percentages represent the proportion of subjects obtaining a score on each item. Bracketed values refer to the results of Halford's research (1991). 
TABLE III

THE INTERCORRELATION MATRIX BETWEEN THE ITEMS OF THE STSS

\begin{tabular}{|c|c|c|c|c|c|c|c|c|c|c|c|c|c|c|c|c|}
\hline & $\begin{array}{c}\text { Item } \\
1\end{array}$ & $\begin{array}{c}\text { Item } \\
2\end{array}$ & $\begin{array}{c}\text { Item } \\
3\end{array}$ & $\underset{4}{\text { Item }}$ & $\underset{5}{\text { Item }}$ & $\underset{6}{\text { Item }}$ & $\begin{array}{c}\text { Item } \\
7\end{array}$ & $\begin{array}{c}\text { Item } \\
8\end{array}$ & $\begin{array}{c}\text { Item } \\
9\end{array}$ & $\begin{array}{c}\text { Item } \\
10\end{array}$ & $\begin{array}{c}\text { Item } \\
11\end{array}$ & $\begin{array}{c}\text { Item } \\
12\end{array}$ & $\begin{array}{c}\text { Item } \\
13\end{array}$ & $\begin{array}{c}\text { Item } \\
14\end{array}$ & $\begin{array}{c}\text { Item } \\
15\end{array}$ & $\begin{array}{c}\text { Item } \\
16\end{array}$ \\
\hline Item 1 & $1.0^{* *}$ & & & & & & & & & & & & & & & \\
\hline Item 2 & .21 & $1.0^{* *}$ & & & & & & & & & & & & & & \\
\hline Item 3 & .17 & .05 & $1.0^{* *}$ & & & & & & & & & & & & & \\
\hline Item 4 & .17 & .22 & .16 & $1.0^{* *}$ & & & & & & & & & & & & \\
\hline Item 5 & -.03 & .05 & .02 & .03 & $1.0 * *$ & & & & & & & & & & & \\
\hline Item 6 & $.30^{*}$ & $.29 *$ & .20 & .02 & .17 & $1.0^{* * *}$ & & & & & & & & & & \\
\hline Item 7 & $.45^{* *}$ & .07 & .13 & .06 & .16 & .13 & $1.0^{* *}$ & & & & & & & & & \\
\hline Item 8 & .18 & .05 & $.30^{* *}$ & .22 & .16 & $.25^{*}$ & $.26^{*}$ & $1.0^{* *}$ & & & & & & & & \\
\hline Item 9 & .11 & -.03 & -.15 & -.13 & .09 & .13 & .15 & -.05 & $1.0^{* *}$ & & & & & & & \\
\hline Item 10 & .12 & .10 & $.30^{* *}$ & .06 & .16 & $.38^{* * *}$ & .06 & .25 & -.00 & $1.0^{* * *}$ & & & & & & \\
\hline Item 11 & .09 & .13 & .10 & -.00 & .01 & .00 & $.30 *$ & .13 & $.30 *$ & .03 & $1.0^{* *}$ & & & & & \\
\hline Item 12 & $.37^{* *}$ & $.24 *$ & $.29^{*}$ & $.43^{* *}$ & .10 & .14 & $.34^{* *}$ & $.41 * *$ & -.05 & .15 & $.25 *$ & $1.0^{* *}$ & & & & \\
\hline Item 13 & $.25^{*}$ & .12 & .20 & $.29 *$ & .06 & .10 & .16 & $.23^{*}$ & .03 & .05 & .10 & $.45^{* *}$ & $1.0^{* *}$ & & & \\
\hline Item 14 & .07 & -.08 & .111 & .09 & .12 & .08 & .07 & $24 *$ & -.05 & .09 & .00 & .11 & .19 & $1.0^{* *}$ & & \\
\hline Item 15 & $.24 *$ & .23 & .06 & .02 & .22 & .17 & .13 & .03 & .07 & .17 & $.25^{*}$ & .19 & .18 & .08 & $1.0^{* *}$ & \\
\hline Item 16 & $.24 *$ & $.29 *$ & .06 & -.07 & .15 & .14 & $.27 *$ & .07 & $.27 *$ & .08 & $.57 * *$ & .14 & .13 & .07 & .14 & $1.0^{* *}$ \\
\hline
\end{tabular}

${ }^{*} p<.01 ;{ }^{* *} p<.001$.

TABLE IV

CORRELATIONS OF THE FOUR FACTORS WITH AUDIOLOGICAL AND PSYCHOLOGICAL VARIABLES

\begin{tabular}{lcccc}
\hline & SCL-90/A & SCL-90/D & UCL/DR & AV \\
\hline Factor 1 & $.28^{*}$ & $.37^{* *}$ & $.28^{*}$ & -.00 \\
Factor 2 & -.05 & -.14 & -.06 & .17 \\
Factor 3 & .15 & .15 & .17 & -.06 \\
Factor 4 & .17 & .09 & .14 & .14 \\
& $(\mathrm{n}=95)$ & $(\mathrm{n}=95)$ & $(\mathrm{n}=95)$ & $(\mathrm{n}=63)$ \\
\hline
\end{tabular}

SCL-90/A: anxiety; SCL/D: depression; UCL/DR: depressive reaction pattern; AV: audiometric variable measuring sensory aspects of tinnitus. One-tailed probability ${ }^{*} p<.01,{ }^{* *} p<.001$.

\section{APPENDIX}

Subjective Tinnitus Severity Scale (STSS) items. The scoring response is bracketed.

1. Does your tinnitus sometimes make it difficult for you to concentrate? (yes)

2. Are you almost always aware of your tinnitus? (yes)

3. Do you find your tinnitus bothers you, when you are doing something physical, like dressing or gardening? (yes)

4. Does your tinnitus cause you problems in getting off to sleep? (yes)

5. Would you say that generally the tinnitus does not bother you? (no)

6. Do you sometimes go for hours without noticing your tinnitus? (no)

7. Is your tinnitus very noisy? (yes)

8. Does your tinnitus frequently upset you? (yes)

9. Do you often have a day or more completely free from tinnitus? (yes)

10. When you are busy, do you often/quite often forget about your tinnitus? (no)

11. Is your tinnitus present for at least part of every day? (yes)

12. Does your tinnitus often interfere with your ability to relax? (yes)

13. Would you say, that although the tinnitus can be irritating, it does not get you down? (no)

14. Do you often talk about the problems your tinnitus causes to others? (yes)

15. Is it unusual for your tinnitus to annoy you when you are trying to read or watch television? (no)

16. Would you say, you would have a much more enjoyable life, if you did not have tinnitus? (yes) 